\title{
Far Eastern Entomologist
}

Number 430: 11-16 $\begin{aligned} & \text { ISSN 1026-051X (print edition) } \\ & \text { ISSN 2713-2196 (online edition) }\end{aligned}$
https://doi.org/10.25221/fee.430.3
http://zoobank.org/References/FD096033-3F0C-4B44-8EEC-4EE8A6F7F478 2021
DEALATE QUEENS OF THE ANT GENUS EURHOPALOTHRIX BROWN
ET KEMPF, 1961 (HYMENOPTERA: FORMICIDAE: MYRMICINAE)
FROM SUMATRA

R. Satria ${ }^{1, *)}$, R. Jannatan ${ }^{2)}$

1) Department of Biology, Faculty of Mathematics and Natural Sciences, Universitas Negeri Padang, West Sumatra, 35171, Indonesia. *Corresponding author. E-mail: rijalsatria@yahoo.co.id,rijalsatria@fmipa.unp.ac.id

2) Department of Biology, Faculty of Mathematics and Natural Sciences, Universitas Andalas, Padang, West Sumatra, 25163, Indonesia.E-mail: robbyjannatan@sci.unand.ac.id

Summary. The hitherto unknown queen of Eurhopalothrix platisquama Taylor, 1990 is described and illustrated. The queen of E. jennya Taylor, 1990 is also redescribed; this species is recorded for the first time from Sumatra Island.

Key words: ants, dealate gyne, description, fauna, new record, Indonesia.

Р. Сатриа, Р. Джаннатан. Бескрылые царицы муравьев рода Eurhopalothrix Brown et Kempf, 1961 (Hymenoptera: Formicidae: Myrmicinae) c Суматры // Дальневосточный энтомолог. 2021. N 430. С. 11-16.

Резюме. Приведено иллюстрированное описание ранее неизвестной царицы муравья Eurhopalothrix platisquama Taylor, 1990. Впервые с острова Суматра указывается E. jennya Taylor, 1990; для этого вида также составлено описание бескрылой царицы.

\section{INTRODUCTION}

The diversity of ants in Sumatra is poorly studied, except for several genera (Terayama \& Yamane, 1989; Agosti, 1992; Satria et al., 2015, 2017; Satria \& Yamane, 2019; Satria \& Herwina, 2020). The genus Eurhopalothrix Brown et Kempf, 1961 (Myrmicinae: Attini) is easily distinguished from the other myrmicine genera by its 7-segmented antenna and triangular mandibles (Brown \& Kempf, 1961; Taylor, 1980; Bolton, 2003). This genus consists of 53 extant valid species widely distributed in the Neotropics and Indo-Australian tropics (http://www.antwiki.org/). The ants of the genus Eurhopalothrix are generally uncommon due to its small size and cryptobiotic nature, and foraging workers always collected from the soil and leaf-litter by proper collection methods (Taylor, 1990). Only three species of the genus were known from Sumatra Island, namely E. coronate Taylor, 1990, E. omnivaga Taylor, 1990, and E. platisquama Taylor, 1990 (Taylor, 1990; Mezger \& Pfeiffer, 2010). During our survey to study the ants in the lowland disturbed forest of West Sumatra Province, we collected the part of two colonies of Eurhopalothrix. In the present study, we described the dealate gyne of two species of this genus, one of which is recorded from Sumatra for the first time. 


\section{MATERIAL AND METHODS}

Species determination of the colony RS6ii2021-SU5 (Eurhopalothrix platisquama) and RS6ii2021-SU6 (E. jennya Taylor, 1990) were done by referring to the descriptions by Taylor (1990) and Mezger \& Pfeiffer (2010). The type material image of E. platisquama (paratype, worker, CASENT0900939) and E. jennya (paratype, worker, CASENT0900937) provided by Antweb (https://www.antweb.org/) was also used for determination.

Multi-focused montage images were produced using Helicon Focus Pro. (Helicon Soft Ltd., http://www.heliconsoft.com/) from a series of source images taken by a Canon EOS KissX5 digital camera attached to a Nikon SMZ1270 stereomicroscope. Artifacts/ghosts and unnecessary parts (unfocused appendages, insect pin, etc.) surrounding or covering target objects were erased and cleaned up using the retouching function of Helicon Focus Pro, and the color balance, contrast, and sharpness were adjusted using Adobe Photoshop CS6.

The parts of the bodies were measured using ImageJ $1.49 \mathrm{~m}$ (National Institute of mental Health, USA, available at http://imageJ.nih.gov/ij/) based on the photographs taken using a Canon EOS KissX5 digital camera attached to the Nikon SMZ1270 stereomicroscope under suitable magnifications. Morphological terminology, abbreviations of measurements and indices follow Taylor (1990) and Mezger \& Pfeiffer (2010).

\section{RESULTS}

\section{Eurhopalothrix platisquama Taylor, 1990}

Figs 1-5

MATERIAL EXAMINED. Indonesia: West Sumatra, Padang, Pauh, Limau Manis, Sarasah Uwak Waterfall, $0^{\circ} 54^{\prime} 47.7^{\prime \prime S}, 100^{\circ} 28^{\prime} 54.8^{\prime \prime} \mathrm{E}$, near the waterfall and disturbed forest, 6.II 2021, colony code RS6ii2021-SU5, 1 dealate gyne and 8 workers, leg. R. Satria.

DESCRIPTION OF DEALATE QUEEN (hitherto unknown). In general, appearance queen is similar to worker, for worker description see Taylor (1990). Head in full-face view subtriangular, slightly longer than broad, with posterior and posterolateral margins almost straight (Fig. 1); ocelli present; distance between lateral ocelli longer than distance between lateral and median ocelli, and four times as long as major axis of median ocellus; ocelli in lateral view slightly protruded dorsad; eye large, with about 114 ommatidia; clypeus in fullface view broader than long, with anterior margin slightly concave; frontal carina bordering deep antennal scrobe below eye, allowing total reception of antenna; antenna 7-segmented; antennal scape expanded anterad; mandible triangular; masticatory margin with nine teeth. Mesosoma with main sclerites associated with wing function (Figs 2, 4), in dorsal view short and stout; anterodorsal slope of pronotum in lateral view steep; anterodorsal outline of mesoscutum in lateral view relatively gentle; propodeal spiracle conspicuous.

Body entirely densely foveolate. Body covered almost entirely by flat-surfaced and squamiform hairs, detail description of these hairs given by Taylor (1990). Head in full-face view, with four standing setae on vertex of head (Fig. 1); antennal scape with two-row of setae at outer edge, first row directly on corner with 10 thick and long setae getting shorter distally; second row with five smaller setae, proximal setae same size of squamiform hairs, but getting larger distally; antennal segments covered with fine simple hairs; pronotum without standing setae; mesoscutum with eight standing setae, with setae on each side of posterodorsal as thick as setae on vertex, and other slender than setae on vertex; mesoscutellum, postpetiole and first gastral tergite with two standing setae as thick as setae on vertex (Figs 2, 4, 5); second and third tergite with four standing setae, second sternite with eight 
standing setae, third sternite with six standing setae, and these setae slender than setae on vertex. For color pattern, see Figs 1-5; head, antennal scape, mesosoma, all legs, petiole, and postpetiole dark reddish-brown, gaster blackish brown; antennal flagellum, tibia, and tarsi paler.

MEASUREMENTS (dealate queen). HL $0.80 \mathrm{~mm}$, HW $0.90 \mathrm{~mm}$, EY $0.17 \mathrm{~mm}$, SL 0.43 $\mathrm{mm}$, SeL $0.06 \mathrm{~mm}$, DSe $0.05 \mathrm{~mm}$, WL $0.96 \mathrm{~mm}$, PW $0.66 \mathrm{~mm}$, PSD $0.06 \mathrm{~mm}$, PeL $0.44 \mathrm{~mm}$, PeW $0.37 \mathrm{~mm}$, PPL $0.39 \mathrm{~mm}$, PPW $0.56 \mathrm{~mm}$, CI 112.
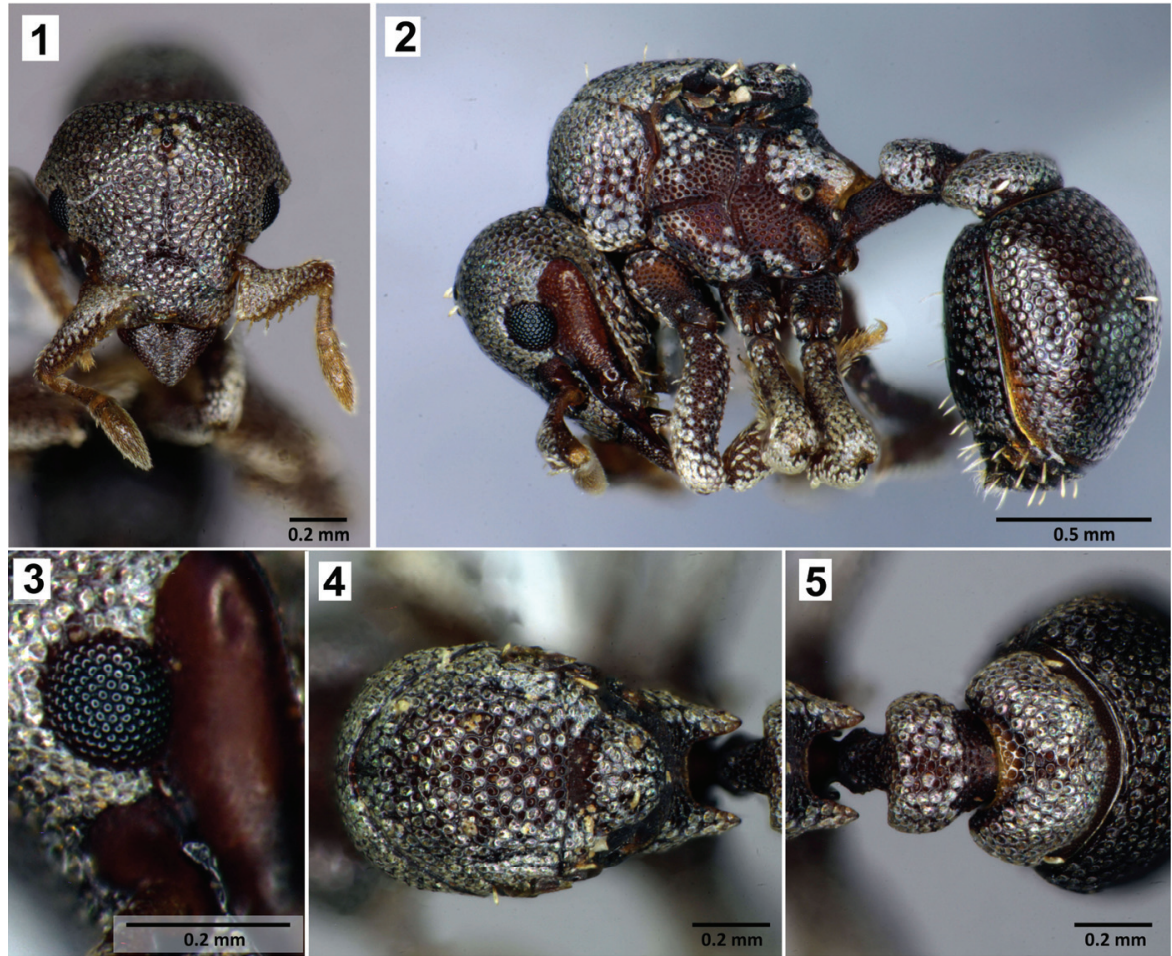

Figs 1-5. Dealate gyne of Eurhopalothrix platisquama (colony: RS6ii2021-SU5, individual: RS9ii2021A). 1 - head in full-face view; 2 - body in lateral view; 3 - eye; 4 mesosoma in dorsal view; 5 - petiole and postpetiole in dorsal view.

REMARKS. So far, only the queens of Eurhopalothrix dubia Taylor, 1990, E. omnivaga Taylor, 1990 and $E$. jennya Taylor, 1990 were described (Taylor, 1990). The queen of $E$. platisquama is easily distinguished from E. dubia by the combination of the following characteristics: head in full-face view with four thick standing setae near ocelli (vs. six thick standing setae in the latter); mesoscutum with eight standing setae, with setae on each side of posterodorsal as thick as setae on the vertex, and other slender than setae on the vertex (vs. six in the latter, with thick setae on each side of posterodorsal, and other slender); postpetiole with two thick standing setae (vs. absent in the latter); first gastral tergite with two thick standing setae (vs. eight in E. dubia). The queen E. platisquama is easily distinguished from 
the queen of E. jennya and E. omnivaga by the presence of flat-surfaced and squamiform hairs in the whole surface of the body and the presence of four thick standing setae near ocelli. The difference between queens of E. jennya and E. omnivaga see in Taylor (1990). The general appearance of each queen is similar to workers, the morphological difference of workers is given by Taylor (1990).

DISTRIBUTION. Indonesia: Sumatra; Malaysia: Malay Peninsula (Taylor, 1990; Mezger \& Pfeiffer, 2010). So far, this species was known from the southern part of Sumatra (Liwa, Lampung Province) (Taylor, 1990; Mezger \& Pfeiffer, 2010; Janicki et al., 2016), while we find it in the middle part of Sumatra (Padang, West Sumatra Province).

\section{Eurhopalothrix jennya Taylor, 1990}

Figs 6-9

MATERIAL EXAMINED. Indonesia: West Sumatra, Padang, Pauh, Limau Manis, Sarasah Uwak Waterfall, $0^{\circ} 54^{\prime} 47.7^{\prime \prime S}, 100^{\circ} 28^{\prime} 54.8^{\prime \prime E}$, near the waterfall and disturbed forest, 6.II 2021, colony code RS6ii2021-SU6, 1 dealate gyne and 7 workers, leg. R. Satria.
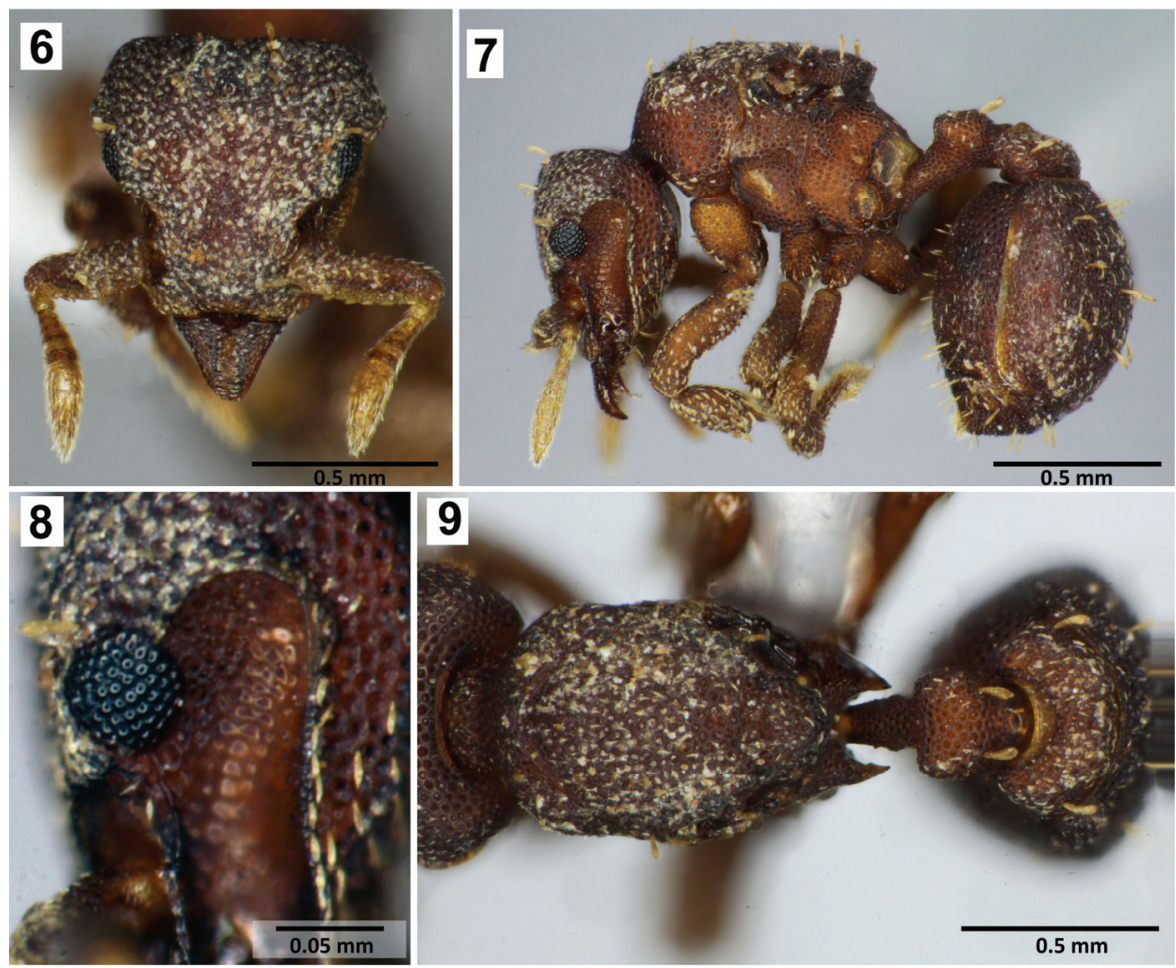

Figs 6-9. Dealate gyne of Eurhopalothrix jennya (colony: RS6ii2021-SU6, individual: RS13ii2021A). 6 - head in full-face view; 7 - body in lateral view; 8 - eye; 9 - mesosoma, petiole and postpetiole in dorsal view. 
REDESCRIPTION OF DEALATE QUEEN. In general appearance, queen is similar to worker, for worker description see Taylor (1990). Head in full-face view subtriangular, slightly longer than broad, with posterior and posterolateral margins almost straight (Fig. 6); ocelli present; distance between lateral ocelli longer than distance between lateral and median ocelli, and four times as long as major axis of median ocellus; ocelli in lateral view slightly protruded dorsad; eye large, with about 60 ommatidia; clypeus in full-face view broader than long, with anterior margin slightly concave; frontal carina bordering deep antennal scrobe below eye, allowing total reception of antenna; antenna 7-segmented; antennal scape expanded anterad; mandible triangular; masticatory margin with 11 teeth. Mesosoma with main sclerites associated with wing function (Figs 7, 9), in dorsal view short and stout; anterodorsal slope of pronotum in lateral view steep; anterodorsal outline of mesoscutum in lateral view relatively gentle; propodeal spiracle conspicuous.

Body entirely densely foveolate. Dorsum of head, posterodorsal surface of pronotum, mesoscutum, dorsum of postpetiole, first gastral tergite, antennal scape, and all legs covered by a ground pilosity of minute scattered hairs, detail description of these hairs given by Taylor (1990). Head in full-face view, with six standing setae on vertex of head (Fig. 6), four on middle near ocelli, and one seta behind each eyes; antennal scape with two-row of setae at outer edge, first row directly on corner with seven thick and long setae getting shorter distally; second row with five smaller setae getting larger distally; antennal segments covered with fine simple hairs; posteromedian of pronotum with two standing setae; antero-lateral of pronotum with eight hairs on each sides, vary in size and getting larger distally; mesoscutum with eight of standing setae, with two pairs relatively short and slender on disc of mesoscutum, and two pairs as thick as setae on vertex in posterolateral and posterodorsal of mesoscutum respectively; mesoscutellum, petiole and postpetiole with two standing setae as thick as setae on vertex (Figs 7-9); first gastral tergum with 14 standing setae; second and third tergite with five standing setae, second and third sternite with six standing setae. For color pattern, see Figs 6-9; body dark reddish-brown, antennal flagellum yellowish.

MEASUREMENTS (dealate queen). HL $0.75 \mathrm{~mm}$, HW $0.80 \mathrm{~mm}$, EY $0.06 \mathrm{~mm}$, SL 0.40 $\mathrm{mm}$, SeL $0.07 \mathrm{~mm}$, DSe $0.21 \mathrm{~mm}$, WL $0.84 \mathrm{~mm}$, PW $0.59 \mathrm{~mm}$, PSD $0.03 \mathrm{~mm}$,PeL $0.37 \mathrm{~mm}$, PeW $0.29 \mathrm{~mm}$, PPL $0.27 \mathrm{~mm}$, PPW $0.51 \mathrm{~mm}$, CI 106.

REMARKS. The queen of Eurhopalothrix jennya was described by Taylor (1990), and he mentions that " 12 hairs are scattered on the first gastral tergum, loosely arranged in 4 longitudinal rows". Interestingly, the Sumatran specimen has 14 thick setae on the first gastral tergite with 12 arranged in four longitudinal rows, and two setae on each of the posterolateral sides of the first gastral tergite. We assumed that probably the paratype queens of $E$. jennya were worn out during preserving the specimens.

DISTRIBUTION. Indonesia: Sumatra (new record); Malaysia: Borneo (Sarawak: Kampong Segu and Gunung Mulu National Park) (Taylor, 1990; Mezger \& Pfeiffer, 2010; Pfeiffer et al., 2015; Janicki et al., 2016).

\section{ACKNOWLEDGEMENTS}

We would like to express our gratitude to Mrs. Vina Zubir, Mr. Zumar Satria, Mrs. Mustika Wulan Dari for their help and hospitality during our field works.

\section{REFERENCES}

Agosti, D. 1992. Revision of the ant genus Myrmoteras of the Malay Archipelago (Hymenoptera,Formicidae). Revue Suisse de Zoologie, 99(2): 405-429. DOI: http://biostor.org/ reference $/ 115025$ 
Bolton, B. 2003. Synopsis and classification of Formicidae. Memoirs of the American Entomological Institute, 71: 1-370.

Brown, W.L. Jr. \& Kempf, W.W. 1961. The type species of the ant genus Eurhopalothrix. Psyche, 67(1-2): 44.

Mezger, D. \& Pfeiffer, M. 2010. Eurhopalothrix elke, a new species from Borneo, and a key to the species of the E. platisquama group. Myrmecological News, 13: 133-139.

Janicki, J., Narula, N., Ziegler, M., Guénard, B. \& Economo, E.P. 2016. Visualizing and interacting with large-volume biodiversity data using client-server web-mapping applications: The design and implementation of antmaps.org. Ecological Informatics, 32: 185-193. DOI: https://doi.org/10.1016/j.ecoinf.2016.02.006

Pfeiffer, M., Mezger, D., Hosoishi, S., Yahya, B.E., \& Kohout, R.J. 2015. The Formicidae of Borneo (Insecta: Hymenoptera): a preliminary species list. Asian Myrmecology, 4: 9-58.

Taylor, R.W. 1980. Australian and Melanesian ants of the genus Eurhopalothrix Brown and Kempf - notes and new species (Hymenoptera: Formicidae). Journal of the Australian Entomological Society, 19(3): 229-239. DOI: https://doi.org/10.1111/j.1440-6055.1980. tb02094.x

Taylor, R.W. 1990. New Asian ants of the tribe Basicerotini, with an on-line computer interactive key to the twenty-six known Indo-Australian species (Hymenoptera: Formicidae: Myrmicinae). Invertebrate Taxonomy, 4(2): 397-425. DOI: https://doi.org/10.1071/ IT9900397

Terayama, M. \& Yamane, Sk. 1989. The army ant genus Aenictus (Hymenoptera, Formicidae) from Sumatra, with descriptions of three new species. Japanese Journal of Entomology, 57(3): 597-603.

Satria, R., Kurushima. H., Herwina, H., Yamane Sk. \& Eguchi, K. 2015. The trap-jaw ant genus Odontomachus Latreille (Hymenoptera: Formicidae) from Sumatra, with a new species description. Zootaxa, 4048(1): 1-36. DOI: http://dx.doi.org/10.11646/zootaxa. 4048.1.1

Satria, R., Viet, B.T. \& Eguchi, K. 2017. New synonymy and redescription of Anochetusmixtus Radchenko, 1993, and distinction from the other members of the Anochetus rugosus Group (Hymenoptera: Formicidae: Ponerinae). Asian Myrmecology, 9, e009006: 1-16. DOI: http://doi.org/10.20362/am.009006

Satria, R. \& Herwina, H. 2020. New distribution record of ants species (Hymenoptera: Formicidae) to the fauna of Sumatra island, Indonesia. International Conference on Biology, Sciences, and Education (ICoBioSE 2019), 10: 82-84.

Satria, R. \& Yamane, Sk. 2019. Two new species of the ant genus Myrmecina (Hymenoptera: Formicidae: Myrmicinae) from Sumatra. Zoosystematica Rossica, 28(1): 183-193. DOI: https://doi.org/10.31610/zsr/2019.28.1.183

(C) Far Eastern entomologist (Far East. entomol.) Journal published since October 1994. Editor-in-Chief: S.Yu. Storozhenko

Editorial Board: A.S. Lelej, S.A. Belokobylskij, M.G. Ponomarenko, V.A. Mutin, E.A. Beljaev, E.A. Makarchenko, A.V. Gorochov, T.M. Tiunova, M.Yu. Proshchalykin, S.A. Shabalin, V.M. Loktionov

Address: Federal Scientific Center of the East Asia Terrestrial Biodiversity (former Institute of Biology and Soil Science), Far East Branch of the Russian Academy of Sciences, 690022, Vladivostok-22, Russia.

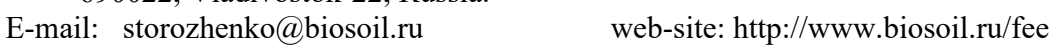

